\title{
The Impact of Dual Agency
}

\author{
J'Noel Gardiner, Park University \\ Jeffrey Heisler, Gottex Fund Mangement \\ Jarl G. Kallberg, New York University \\ Crocker H. Liu, Arizona State University
}

In 1984, the State of Hawaii's legislature enacted a law making it mandatory for real estate agents engaged in dual agency relationships (i.e., when the seller's and the buyer's agents are employed by the same real estate firm) to disclose this fact to both parties in writing. The assumption was that the dual agency relation was damaging to the seller. This study analyzes the effect of disclosed and undisclosed dual agency, and the impact of the legislation, using data prior to and after the legislation (approximately 2,000 residential sales in each period). To account for property characteristics, hedonic models for the log of sale price and for the log of days on market are estimated in each period. Our empirical analysis suggests that dual agency significantly reduced the sales price, but the influence was much smaller after the legislation (8.0 versus 1.4\%). In addition, dual agency significantly decreased the time on market by approximately $8.5 \%$ pre-legislation and $8.1 \%$ post-legislation, although the influence was much stronger for lower priced residences. These results are confirmed using a seemingly unrelated regression model.

\section{Introduction}

In 1984, the State of Hawaii's legislature enacted a law requiring real estate agents engaged in dual agency relations (i.e., when the seller's and buyer's agents work for the same real estate firm) to disclose this fact to both parties in writing. The legislation was motivated by concerns that dual agency creates wealth transfers to real estate agents from the consumers selling or buying the house. However, the actual situation is ambiguous. The two principals have somewhat opposing objectives: the seller wants the highest price possible, the buyer seeks the lowest, while both parties benefit from a timely completion of the transaction. Dual agency creates an informational advantage for the dual agent acting as the market maker since both principals reveal information about their respective bid and ask prices. It 
is plausible that the agents will use this superior information to extract rents from the buyer or seller. However, dual agency should also create a higher probability of finding an acceptable transaction price; both buyer and seller would thus benefit from having the transaction completed more quickly. Since the agents are compensated directly by the seller as a percentage of the sales price, there arises a tension between commission and effort. It is not clear whether the matching between seller and potential buyers can be best expedited by convincing the seller to accept a lower price or convincing the seller to accept a higher price than that which would have been achieved without the dual agency relation. Thus dual agency might lead to different transaction prices and time on the market than would be the case if the buyer's and seller's agents acted independently. However, the overall effect on the principals is not obvious.

This legislation provides an ideal experimental setting to evaluate the economic impact of agency relations in basic financial transactions. We use a sample of nearly 4,000 sales of residential properties from the Honolulu area; this sample is almost equally partitioned into observations prior to and after the legislation. The legislation allows us to examine the role of dual agency in a setting where it is undisclosed and then, after the legislation, in a situation where market participants are aware of the dual agency. The purpose of this study is straightforward: to examine the economic impact of dual versus non-dual agency transactions as well as the effect of legislated disclosure of a dual agency relation. The empirical questions we ask are the following:

- Does dual agency influence the selling price or the amount of time it takes to sell a residence?

- Does the mandated disclosure of dual agency influence the behavior of agents and principals? I.e., does informing the buyer and seller about the presence of dual agency reduce the tendency of agents to exploit this relation?

- As the proponents of the legislation claimed, is there a wealth transfer from seller to buyer because of the existence of a dual agency relation?

Our findings can shed light on the dynamics of agency relationships in an "island" economy. It can also have practical policy implications as other jurisdictions consider the suitability of adopting Hawaii's disclosure law. ${ }^{1}$ These issues are particularly relevant in our current housing boom since numerous consumer advocates (including Ralph Nader) have suggested that real estate agents are exploiting their relative informational advantage.

\footnotetext{
${ }^{1}$ Brown et al. (1995) note that, since 1988, 26 states have modified their real estate agency laws.
} 
The main focus of this study is thus to contribute to the surprisingly small literature dealing with empirical analyses of agency relations. Our null hypothesis is that the costs of dual agency are not economically significant: i.e., there are no significant differences in selling price or time on market between dual and non-dual listings. This hypothesis is tested separately in the periods before and after the enactment of the disclosure legislation. To account for property characteristics, hedonic models for the log of sale price and log of days on market are estimated. Briefly stated, our empirical analysis provides the following results:

- The legislation significantly reduced the frequency of dual agency. In the pre-legislation period $43.8 \%$ ( 872 out of 1,989 ) of all listings were dual listings; in the second period this percentage declined to $28.2 \%$ (523 out of 1,858 ).

- In each period, the univariate statistics indicate that dual listings have lower mean and median (listing and sale) prices than non-dual listings, although none of these differences are statistically significant.

- A dummy variable for dual agency in the hedonic model for the log of sales price has a negative and significant coefficient in both periods, although its magnitiude is significantly lower in the post-legislation period; in the pre-legislation period dual agency reduced the sales price by approximately $8.0 \%$; in the post-legislation period the reduction was only $1.8 \%$.

- A dummy variable for dual agency in the hedonic model for the log of days on market has a, very similar, negative significant coefficient in both periods, although, perhaps surprisingly, this effect is stronger for houses sold below the median price: dual agency reduced the time to sale for lower priced houses by approximately $11.6 \%$ and for houses above the median price by an insignificant amount.

- Estimating the two equations using a seemingly unrelated regression model does not materially influence the above results.

Thus, although the univariate statistics do not detect any significant differences due to dual agency, the hedonic models demonstrate that dual agency had a significant economic impact and further that the legislation significantly impacted the sale price but not the days on market.

The remainder of the paper is organized as follows: "Literature Review" briefly reviews the relevant literature. The third section describes the legislation. "Data and Methodology" describes our data and overviews our methodology. The fifth section summarizes our results and the final section presents our conclusions. 


\section{Literature Review}

The implications of principal-agent models in a dual agency setting are ambiguous. If it is assumed that the dual agent has an informational advantage, superior knowledge of the buyer's demand curve could allow the agent to negotiate a higher sale price (and thus a higher commission) for the seller than a non-dual agent. The opposite conclusion might be drawn from the standard principalagent settings. Holmström (1979) and others assume the agent maximizes utility of expected total profit and minimizes disutility of effort; thus, dual listings might present an opportunity to complete the transaction quickly. ${ }^{2}$ This is best accomplished by matching the buyer and the seller within the agency at a relatively low sale price. The result would be a transfer of wealth from the seller to the buyer. ${ }^{3}$ Mitigating the broker's incentives to exploit this informational advantage are reputation effects. Since every buyer is a potential seller, there is a tension between the short-term strategy of informational opportunism and the long-term strategy of developing a reputation. These dynamics are an essential component of most models of reputation; see, for example, Shapiro $(1982,1983)$ and Diamond $(1989)$.

In real estate markets the principal-agent relation is typically framed in terms of search costs and market liquidity. Yinger (1981) models the real estate market as an auction with a positive externality in market size (liquidity). Since the number of buyers and sellers entering the market in each period is stochastic, a larger market lowers search costs, increases the probability of a match and lowers price uncertainty. ${ }^{4}$ As a consequence, he recommends mandatory multiple listing service (MLS) listing. Frew (1987) extends this model to incorporate competition. Although the MLS improves liquidity, it increases the likelihood of a split commission. The result is a separating equilibrium where large agencies withhold listings, while smaller agencies voluntarily list. Although these liquidity models suggest that larger firms would be more likely to engage in dual listing (the lower search cost making it optimal to withhold listing and retain the higher commission), they have little to say about the impact such listings have on the sale price or listing time. Yavas (1992) presents a theoretical model of the impact of engaging a broker. He shows that a seller obtains a higher price when she engages a broker, but that the size of the commission more than offsets this gain. ${ }^{5}$ Yavas (1995) describes a search model

\footnotetext{
${ }^{2}$ See also Williams (1995). For an overview of the literature on incentives in the principal-agent framework see Sappington (1991).

${ }^{3}$ Related empirical work can be found in Case and Shiller (1989) and Genesove and Mayer (1997).

${ }^{4}$ Wheaton (1990) develops a dynamic model focusing on the short- and long-term relations between turnover, search and pricing. Mayer (1995) adapts this model to real estate auctions.

${ }^{5}$ Springer (1996) uses an extensive sample of sales of single-family dwellings to address the impact of seller motivation.
} 
with multiple equilibria in which the existence of brokerage can have either a positive or negative impact on total welfare. Salant (1991) develops the seller's optimal pricing decision in a multi-period setting with and without a broker.

There are two empirical studies that are closely related to this paper: Curran and Schrag (2000) and Rutherford et al. (2005). The latter paper, using a large sample of residential property transactions from 1998 to 2002, finds evidence of significant agency costs. They estimate that agent-owned homes sell at a premium of $4.5 \%$ over other homes, although the time on the market for these two types of transactions is not significantly different. Somewhat closer to our study is Curran and Schrag (2000). They investigate the economic effects of the 1994 revision in Georgia's real estate law. This legislation required fuller disclosure of agency relations and shifted the focus of real estate agents from exclusively serving the interests of the seller, to one where agents also serve the buyer. ${ }^{6}$ This legislation reduced the seller's information set by, i.a., restricting the amount of information a buyer's agent could disclose to a seller. Similar to our approach, they use a hedonic pricing model to gauge the economic significance of the law. However, there are several important distinctions between their analysis and ours. Most importantly, their paper focuses on the aggregate effect of a shift to buyer's agency, ${ }^{7}$ which clearly makes the seller worse off. ${ }^{8}$ While our results complement those of Curran and Schrag, we emphasize the impact of dual agency before and after the legislation, which, as noted earlier, is not obviously an advantage to either the seller or buyer. Their empirical tests find that a residence's average days on the market fell, but that prices declined only for relatively more expensive residences. Our tests, on the other hand, have three aspects: using data from the pre-legislation period, we gauge the economic impact of undisclosed dual agency; using data from the post-legislation period, we estimate the effect of disclosed dual agency; thirdly, comparing the effects across the two periods, we ascertain the impact of the legislation on agents' behavior.

\section{Legislation}

Prior to 1984, Hawaiian real estate agents did not have to reveal the dual agency relation to either principal. The Hawaii Real Estate Commission studied the legal and practical issues concerning

\footnotetext{
${ }^{6}$ The bargaining problem between the seller and buyer is analyzed in Yavas (1992) and Bajtelsmit and Worzala (1997).

${ }^{7}$ Elder et al. (2000) show that buying agents tend to reduce the days on market but have no effect on selling price. In an experimental study, Yavas et al. (2001) suggest that the benefits of brokerage lie more with the matching rather than the bargaining process. Anglin (1997) provides related theoretical results.

${ }^{8}$ In most jurisdictions, the buyer's agent is effectively a subagent of the seller's broker and thus has a fiduciary responsibility to the seller.
} 
agency relationships in real estate transactions for more than 4 years prior to the passage of the law. The law, which is contained in Chapter 467-14(12) Hawaii Revised Statutes and Chapter 16-99-3.1 Hawaii Administrative Rules, became effective July 1, 1987 and July 11, 1987, respectively.

The law requires that the salesperson make early disclosure of whom he or she represents and to note in writing in the sales contract that this disclosure was made. The law requires the listing and selling brokers to make two disclosures of agency representation to both the buyer and the seller. One is prior to the signing of documents and the second at the time that the documents are signed. The written consent must state that the licensee has made full disclosure regarding the type of representation the licensee will provide. For example, will the broker act as a mere conduit of information or will the broker actively negotiate for both sides? Will the broker maintain or reveal confidential information such as price, terms, personal motivation and financial matters? The listing broker is also required to ask the seller whether the seller permits the use of subagents and the sharing of commissions with the seller's subagent or the buyer's agent.

According to Hawaiian law: ${ }^{9}$

A dual agent is an agent for two principals. A real estate broker, acting directly or indirectly through salespeople in the firm, sometimes represents both the buyer and the seller (or the lessee and the lessor). Such dual representation is not illegal provided full disclosure has been made to both and their consent has been obtained. If the broker has not given full disclosure and obtained the informed consent of the principals involved to act as a dual agent, serious liability and risks occur, including possible rescission of the contract, forfeiture of commission, loss of license, and actual money damages ... Hawaii law specifically prohibits brokers from acting as undisclosed dual agents (HRS 467-14[4]). The reason for disclosure is to help consumers and licensees avoid undisclosed and unintended dual agency relationships. No matter who the licensee represents, the licensee owes general obligations of fairness and honesty to the buyer and the seller. The licensee must service the interests of both as best as possible.

The licensee does not necessarily represent the seller even if the seller pays the commission. Existing case law is confirmed in that the agency disclosure states "the obligation of either the seller or buyer to pay compensation to a broker is not determinative of the agency relationship."

These potential problems have long been recognized; see, for example, FTC (1983) and Bryant and Epley (1992). Related legislation remains debated in other jurisdictions and in the popular press. ${ }^{10}$

\footnotetext{
${ }^{9}$ See “Understanding Agency Disclosure," Hawaii Real Estate Commission, July 1, 1987.
} 
To give just one example, we have the following melodramatic excerpt from the Wall Street Journal, Blumenthal (1995):

Sitting at her kitchen table mulling two offers for her Dallas home, Joan Preston wanted some advice from her real estate brokers. But the brokers were double agents. The team she had hired was representing both her and the buyers, meaning they couldn't really advise either.

\section{Data and Methodology}

The transactions data are gathered manually from the Multiple Listing Service (MLS) of Sold Properties from the Honolulu Board of Realtors (HBR). The periods examined are 1977-1980 and 19871989. The HBR was the sixth most active residential real estate market in the US over this time period. These intervals are chosen to provide a reasonable distance from the legislation's enactment. The 4-year gap before legislation ensures that the data are not significantly contaminated by discussion of the impending legislation. The 3-year time interval afterward allows market participants time to adjust to the new legal regime. Since our data are comprised of completed transactions, we are unable to assess the impact of dual agency on the possibility of successfully matching buyer and seller. However, our analysis of the effect of dual agency on days to sale will indirectly address this issue.

The data are fairly representative of overall real estate transactions in Oahu during this time interval. Our data however, are restricted to residential properties in order to allow a more parsimonious hedonic pricing model. Figure 1 shows the number of listings and sales over all of Oahu during this period. These data include our sample of single-family dwellings as well other types of real estate: condos, co-ops, vacant land, apartments and commercial properties. Figure 2 shows the average selling price for single-family dwellings over the sample period; the data show an average yearly increase of $\$ 13.1$ thousand.

All of the listing contracts in our sample are exclusive right to sell contracts, which give a broker an exclusive right to sell the property. The seller agrees to pay the broker the commission no matter who finds the buyer. Even if the seller finds a buyer directly, the exclusive broker is paid a commission. This form of contract is typically required in order to use a multiple listing service (MLS). Under an MLS arrangement, a group of brokers share a pool of listings. The selling agent is thus assured of compensation when working through a subagency agreement with the listing broker. For inclusion in the

\footnotetext{
${ }^{10}$ See Curran and Schrag (2000) for further discussion and an overview of the relevant case history.
} 
Honolulu MLS, only exclusive right to sell and exclusive agency listings ${ }^{11}$ are accepted. For each listing, if the list broker and sale broker were from the same agency, the transaction was counted as a dual listing.

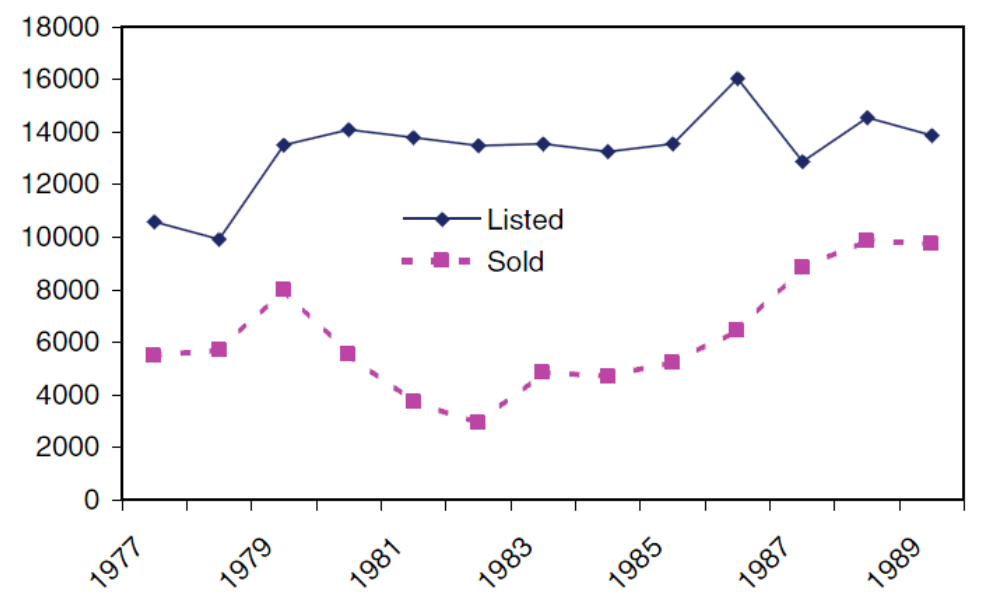

Fig. 1 Listings versus sales during sample period. This figure shows the number of listings versus sales for multiple listings over the entire island of Oahu during the sample interval. The data include singlefamily dwellings as well as condos, coops, vacant land, apartments and commercial properties. On average, $47 \%$ were sold, although this figure is higher in the second part of our sample

Commission levels for residential real estate in Hawaii are $6 \%$ of the total sales price.

Commissions are typically split equally between the listing and cooperating brokers. Each office then pays its participating agent a percentage of the total. If an office is part of a franchise system, the commission paid to agents within that office is reduced by the franchising charges. Based on one of the co-author's experience as a salesman in Honolulu during our study period, the broker listing the property typically received $20-40 \%$ of the $3 \%$ commission paid to his or her firm. In contrast, the broker who sold the property received about $50-60 \%$ of his or her firm's $3 \%$ commission. As such, an agent who listed and sold the property received about $80 \%$ of the $6 \%$ commission. This commission percentage increases the higher the transaction volume of an agent. Further increasing the potential agency problems, many offices pay a higher commission for dual (also called "in house") sales, where both the listing and selling agent are from the same agency (but are not necessarily the same agent). In this case, the agency's income increases since the commission is not shared with another office. ${ }^{12}$

The variables examined describe the transaction [list price (LISTP), sale price (SALEP), days on market (DOM), year sold (YR)] and the property's characteristics [fee simple (FSLH) and the log of total

\footnotetext{
${ }^{11}$ Exclusive agency listings are similar to exclusive right to sell listings except that, in the first case, if the seller finds a buyer, the listing broker receives no commission.

12 Our analysis does not include the impact of closing costs; this is analyzed in Black and Nourse (1995).
} 
assessed value (TASS)]. ${ }^{13}$ The econometric analysis focuses on a dummy variable indicating a dual agency relationship (DUAL); DUAL=1 if the transaction is a dual listing and 0 otherwise. These characteristics are used to estimate hedonic models for the log of sale price and log of days on market. The basic methodology is based on Bryan and Colwell (1982). There were not sufficient data in our sample to attempt a pricing model based on repeat sales. ${ }^{14}$ For brevity, in the following analysis we emphasize results for the entire region; the same analysis was done for each of the 12 school districts in our sample area: Aiea, Hawaii Kai, Kailua, Kalama Valley, Kanaohe, Koko Kai, Mililani, Pacific Palisades, Pearl City, Pearl Ridge, Waiau and Waipahu. These results are qualitatively the same as those obtained for the region and are available from the authors upon request.

\footnotetext{
${ }^{13}$ In an earlier version of this study, a broad array of property characteristics (e.g., square footage, number of bedrooms, presence of a pool, etc.) was used in the hedonic models. For brevity, here we use only the log of the total assessed value, which captures these static characteristics with almost no loss of statistical power or influence on the parameters of interest.

${ }^{14}$ See Clapp and Giacotto (1992) for a comparison of repeat sales versus assessed value methods for determining residential property price indexes.
} 


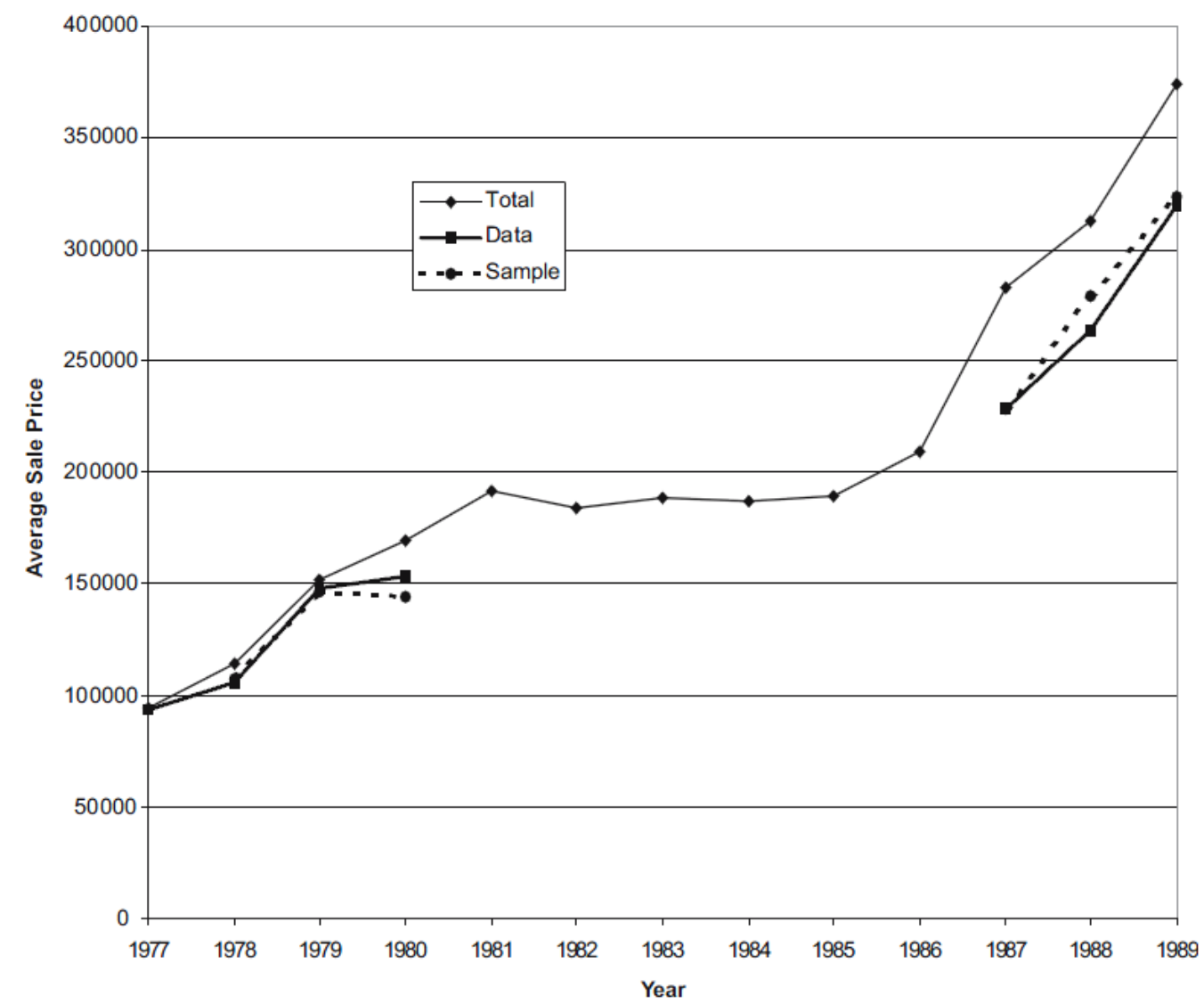

Fig. 2 Sales price over sample interval (Single-family only). This figure shows the average sales price for multiple listings over the entire island of Oahu (Total), the total database (Data), and the sample used for this study (Sample) for single-family dwellings. This sample was the subset of the entire data set for which there were no missing variables

\section{Results}

\section{Univariate Analysis}

We first analyze the univariate statistics to document the basic characteristics of dual and nondual transactions. We then estimate hedonic models in each sub-period to test whether or not the incidence of dual agency (modeled as a dummy variable) is a significant factor in determining the sale price or days on market. Our data are almost equally distributed into the two sub-periods. The first sample period contains 1,989 observations, of which $43.8 \%$ are dual listings. The second period has 1,858 listings, of which only $28.1 \%$ are dual listings. ${ }^{15}$ Thus, we can see that the legislation significantly reduced the percentage of houses that were sold under a dual agency relationship. However, this tells

\footnotetext{
${ }^{15}$ The following tables report results after the deletion of 25 outliers (extreme residuals), most probably representing data errors.
} 
us nothing about the economic significance of this reduction. The largest 17 (16) firms in the 1977-1980 (1987-1989) period account for $45.7 \%(43.8 \%)$ of all listings and $52.0 \%$ (59.7\%) of all dual listings.

Although the number of listings increased, while the number of dual agency transactions declined between periods, the percentage of listings attributed to the larger firms remained reasonably constant. This implies that the decline in dual listings was general, rather than concentrated among the large firms where we might expect the dual agency phenomenon to be more pervasive.

Table 1 gives the basic statistics for each sub-period. In period one, the mean listing price (LISTP) is $\$ 132,850$ and ranges from $\$ 12,500$ to $\$ 1,200,000$. The mean selling price was $\$ 128,440$. The difference in selling price between dual and nondual listings was $-\$ 5,580$. Although this difference is small relative to its population standard deviation $(59,260)$, it does suggest that dual listing is not concentrated on more valuable properties. The average days on market (DOM) in the first period is 54.96 days. This figure is very similar for dual and non-dual listings: 53.81 and 55.85, respectively. Thus, dual listings exhibit a slightly larger decline from listing to sale price and a slightly shorter days on market.

In the post-legislation period, the mean sale price jumped to $\$ 308,670$, but the general characteristics documented for the first period are preserved. Days on market increased by 13.19 days. In the second period, there were no significant differences between the mean percentage price change (again slightly more negative for dual listings), sale price (again slightly lower for dual listings) and days on markets (now 3.90 longer for dual listings). Due to the high degree of variability in our data, this univariate analysis fails to provide evidence of statistically significant economic gains or losses to sellers or buyers in either period due to the incidence of dual agency. ${ }^{16}$ We now try to determine if more precise statistical tests confirm these results.

\footnotetext{
${ }^{16}$ Although not reported here, these characteristics are also preserved when we turn our attention to the 12 individual districts. In particular, the frequency of dual agency was significantly lower across all districts in the second period.
} 
Table 1 Summary statistics

\begin{tabular}{|c|c|c|c|c|c|}
\hline Variable & LISTP $(\$ 000)$ & SALEP $(\$ 000)$ & FSLH & TASS $(\$ 000)$ & DOM \\
\hline \multicolumn{6}{|l|}{$1977-1980$} \\
\hline \multicolumn{6}{|c|}{ All transactions $(N=1,989)$} \\
\hline Mean & 132.85 & 128.44 & 0.374 & 53.49 & 54.96 \\
\hline Median & 120.00 & 117.50 & 0 & 50.42 & 37 \\
\hline Standard deviation & 64.98 & 59.26 & 0.484 & 18.25 & 57.31 \\
\hline $\operatorname{Max}$ & $1,200.00$ & 897.50 & 1 & 311.20 & 525 \\
\hline Min & 12.50 & 12.50 & 0 & 13.35 & 0 \\
\hline \multicolumn{6}{|l|}{ Dual $(N=872)$} \\
\hline Mean & 130.63 & 125.31 & 0.380 & 52.92 & 53.81 \\
\hline Median & 67.78 & 115.00 & 0 & 49.48 & 37 \\
\hline Standard deviation & 119.00 & 56.90 & 0.486 & 17.70 & 55.92 \\
\hline Max & $1,200.00$ & 800.00 & 1 & 169.43 & 522 \\
\hline Min & 44.00 & 45.00 & 0 & 18.23 & 0 \\
\hline \multicolumn{6}{|l|}{ Non-dual $(N=1,117)$} \\
\hline Mean & 134.58 & 130.89 & 0.370 & 53.94 & 55.85 \\
\hline Median & 124.00 & 120.00 & 0 & 50.98 & 38 \\
\hline Standard deviation & 62.69 & 60.95 & 0.483 & 18.67 & 58.38 \\
\hline $\operatorname{Max}$ & 897.50 & 897.5 & 1 & 311.40 & 525 \\
\hline Min & 12.50 & 12.50 & 0 & 13.35 & 0 \\
\hline \multicolumn{6}{|l|}{$1987-1989$} \\
\hline \multicolumn{6}{|c|}{ All transactions $(N=1,858)$} \\
\hline Mean & 325.46 & 308.67 & 0.762 & 179.31 & 68.15 \\
\hline Median & 265.00 & 255.00 & 1 & 158.50 & 40 \\
\hline Standard deviation & 306.97 & 264.98 & 0.426 & 84.97 & 77.52 \\
\hline $\operatorname{Max}$ & 5800.00 & $5,000.00$ & 1 & $1,120.28$ & 552 \\
\hline Min & 90.00 & 85.00 & 0 & 39.19 & 1 \\
\hline \multicolumn{6}{|l|}{ Dual $(N=523)$} \\
\hline Mean & 322.68 & 302.27 & 0.765 & 175.44 & 70.95 \\
\hline Median & 259.00 & 247.50 & 1 & 156.44 & 40 \\
\hline Standard deviation & 316.12 & 256.53 & 0.425 & 79.89 & 84.92 \\
\hline Max & $4,700.00$ & $3,870.00$ & 1 & 878.49 & 552 \\
\hline Min & 90.00 & 85.00 & 0 & 39.19 & 1 \\
\hline \multicolumn{6}{|l|}{ Non-dual $(N=1,335)$} \\
\hline Mean & 326.55 & 311.17 & 0.760 & 180.82 & 67.05 \\
\hline Median & 265.00 & 257.50 & 1 & 159.13 & 40 \\
\hline Standard deviation & 303.43 & 268.27 & 0.427 & 86.86 & 74.43 \\
\hline $\operatorname{Max}$ & $5,800.00$ & $5,000.00$ & 1 & $1,120.28$ & 551 \\
\hline Min & 97.00 & 90.00 & 0 & 55.23 & 1 \\
\hline
\end{tabular}

This table reports the summary statistics for the properties in our data set. The variables are: list price (LISTP), sale price (SALEP), occurrence of fee-simple contracts (versus leasehold) (FSLH), total assessed value (TASS) and days on market (DOM). The number of observations in each group in denoted by $N$

\section{Hedonic Model for Sale Price}

The first regression estimated was a linear hedonic model within each sample period for sale price.17 To correct for heteroscedasticity, we use the log of sales as the dependent variable and we employ iterative, reweighted least squares using biweight weights.18 The weight on observation $\mathrm{i}$ is thus

\footnotetext{
${ }^{17}$ Models for each district were also estimated. Other than a generally better fit, these models share the characteristics of the pooled regression results reported here.

${ }^{18}$ The biweight scheme was the most successful in correcting for heteroscedastic errors. Regressions results (available from the authors) were also obtained using: the White correction for robust standard errors, weighted
} 
$w_{i}=\left[1-\left(\frac{u_{i}}{c_{b}}\right)^{2}\right]^{2}$ if $\left|u_{i}\right| \leq c_{b}$

\section{0 otherwise}

with $u_{i}=\frac{e_{i}}{\sigma_{i}}$, the error over the estimated standard deviation; the constant $c_{b}=4.685$, its standard value.

Table 2 reports coefficient estimates and adjusted $R 2$ values. The table reports the data segregated by period and by sales price. Table 2 gives the estimation for transactions below and above the median value in each period, respectively. However, here the estimation results are essentially independent of this size partitioning. The overall fit in each subsample is good: the adjusted R2s range from 57 to $81 \%$. The dominant independent variable is the log of the total assessed value (InTASS), which captures the static characteristics of the residence; higher assessed values naturally lead to higher sales prices. Dummy variables for years capture macroeconomic effects and the trend in prices. Each of the residences in our sample is classified as fee-simple, which corresponds to outright ownership of the land, or leasehold, meaning that the property is under a long-term lease. Not surprisingly, the dummy variable for fee-simple adds very significantly to the sale price. Most relevant for our analysis are the coefficients on the dummy flagging a dual agency relationship. In each of the subsamples the coefficient is negative and significant, suggesting that the presence of dual agency significantly reduced the selling price. The most important aspect of Table 2 is the relative magnitude of the dual variable coefficient in the pre- and post-legislation periods. Prior to the legislation the coefficient was approximately -0.08 (roughly corresponding to a $8 \%$ decline in sales price due to dual agency), while in the post-legislation period this value was approximately -0.015 . This suggests that the legislation significantly reduced dual agency's impact on sale price. ${ }^{19}$

least squares (WLS) using variance proportional to the square of the mean, GLS using Huber weightings and iterative re-weighted least squares using Huber weightings.

${ }^{19} \mathrm{~A}$ test that the dual coefficient is smaller in the second period was significant at the 0.02 level. 
Table 2 Sales price hedonic model

\begin{tabular}{|c|c|c|c|}
\hline & Coefficient & $t$-stat & $P$-value \\
\hline \multicolumn{4}{|c|}{$\begin{array}{l}1977-1980 ; \text { observations below the median } \\
R^{2}=0.7405\end{array}$} \\
\hline Intercept & 1.786 & 31.23 & 0.00 \\
\hline dual & -0.079 & -2.70 & 0.01 \\
\hline yr78 & 0.121 & 8.90 & 0.00 \\
\hline yr79 & 0.361 & 27.46 & 0.00 \\
\hline fslh & 0.093 & 14.17 & 0.00 \\
\hline lntass & 0.680 & 56.93 & 0.00 \\
\hline \multicolumn{4}{|c|}{$\begin{array}{l}1987-1989 ; \text { observations below the median } \\
R^{2}=0.5748\end{array}$} \\
\hline Intercept & 1.696 & 25.22 & 0.00 \\
\hline dual & -0.017 & -2.05 & 0.05 \\
\hline yr88 & -0.376 & -17.06 & 0.00 \\
\hline yr89 & -0.253 & -10.16 & 0.00 \\
\hline fslh & 0.121 & 14.20 & 0.00 \\
\hline lntass & 0.762 & 44.85 & 0.00 \\
\hline \multicolumn{4}{|c|}{$\begin{array}{l}1977-1980 ; \text { observations above the median } \\
R^{2}=0.7573\end{array}$} \\
\hline Intercept & 0.565 & 8.98 & 0.00 \\
\hline dual & -0.081 & -2.27 & 0.04 \\
\hline $\mathrm{yr} 78$ & 0.487 & 17.65 & 0.00 \\
\hline yr79 & 0.607 & 33.62 & 0.00 \\
\hline fslh & 0.125 & 13.92 & 0.00 \\
\hline Intass & 0.969 & 80.79 & 0.00 \\
\hline \multicolumn{4}{|c|}{$\begin{array}{l}1987-1989 ; \text { observations above the median } \\
R^{2}=0.8062\end{array}$} \\
\hline Intercept & 1.179 & 24.39 & 0.00 \\
\hline dual & -0.012 & -2.59 & 0.02 \\
\hline yr88 & -0.684 & -45.66 & 0.00 \\
\hline yr89 & -0.526 & -37.23 & 0.00 \\
\hline fslh & 0.117 & 14.58 & 0.00 \\
\hline lntass & 0.961 & 91.47 & 0.00 \\
\hline
\end{tabular}

This table reports regression coefficients for the sales price hedonic model. The dependent variable is the $\log$ of sales price. The independent variables are: dual (a dual variable indicating the presence of dual agency), dummy variables for year of sale and fee-simple contracts $(f s l h)$, and the log of the total assessed value of the residence (lntass). Heteroscedasticity is corrected using a biweighting algorithm. This table presents the estimation in pre- and post-legislation period for observations below the median sales price in each period and the data for observations above the median price

\section{Hedonic Model for Days on Market}

Similarly, we estimate a hedonic model for the log of days on market. As noted earlier, the average days on market increased by 13.19 days in the post-legislation period. This model has much less predictive ability than our sale price model, as expected; the adjusted R2 values range from 8 to $10 \%$. As in Table 2, Table 3 splits the sample into observations below and above the median sales price in each period. We use the same independent variables as in the sale price hedonic model, but add the log of the difference between the list and sales price, which proxies for the level of market activity. The estimated coefficients show that, in each subsample, more expensive houses and houses with a fee- 
simple structure take longer to sell. The market activity indicator has the expected positive sign and is strongly significant in each subsample. Here the behavior of the observations based on sales price is quite striking. For lower priced transactions, the dual variable is negative and significant in both periods; its magnitude suggests that the presence of dual agency reduced the days on sales by approximately $11.5 \%$, and, more importantly, this figure was relatively unaffected by the legislation. In contrast, in the sample containing higher sales prices, the dual dummy coefficient is never significant. This result is perhaps unexpected and is consistent with the notion that agents may exploit the dual agency relation more for less expensive houses for which there is a more active market, and potentially less experienced buyers and sellers.

Table 3 Days on market hedonic model

\begin{tabular}{|c|c|c|c|}
\hline & Coefficient & $t$-stat & $P$-value \\
\hline \multicolumn{4}{|c|}{$\begin{array}{l}1977-1980 ; \text { observations below median sale price } \\
R^{2}=0.0758\end{array}$} \\
\hline Intercept & 2.398 & 5.19 & 0.00 \\
\hline dual & -0.119 & -2.47 & 0.01 \\
\hline yr78 & -0.010 & -0.09 & 0.93 \\
\hline yr79 & 0.003 & 0.03 & 0.98 \\
\hline fslh & 0.174 & 3.44 & 0.00 \\
\hline In (Listp-Salep) & 5.405 & 11.22 & 0.00 \\
\hline lntass & 0.249 & 2.59 & 0.01 \\
\hline \multicolumn{4}{|c|}{$\begin{array}{l}1987-1989 ; \text { observations below the median sale price } \\
R^{2}=0.0787\end{array}$} \\
\hline Intercept & 2.032 & 5.01 & 0.00 \\
\hline dual & -0.113 & -2.35 & 0.02 \\
\hline yr88 & -0.010 & -0.07 & 0.94 \\
\hline yr89 & -0.401 & -2.68 & 0.01 \\
\hline fslh & 0.187 & 3.68 & 0.00 \\
\hline In (Listp-Salep) & 5.316 & 11.07 & 0.00 \\
\hline lntass & 0.343 & 3.35 & 0.00 \\
\hline \multicolumn{4}{|c|}{$\begin{array}{l}1977-1980 ; \text { observations above median sale price } \\
R^{2}=0.0945\end{array}$} \\
\hline Intercept & 0.140 & 0.29 & 0.77 \\
\hline dual & -0.050 & -0.79 & 0.43 \\
\hline $\mathrm{yr} 78$ & 1.054 & 5.31 & 0.00 \\
\hline yr79 & 0.621 & 4.66 & 0.00 \\
\hline fslh & 0.005 & 0.08 & 0.94 \\
\hline In (Listp-Salep) & 4.423 & 9.44 & 0.00 \\
\hline lntass & 0.638 & 6.85 & 0.00 \\
\hline \multicolumn{4}{|c|}{$\begin{array}{l}1987-1989 ; \text { observations above median sale price } \\
R^{2}=0.0996\end{array}$} \\
\hline Intercept & 0.775 & 1.88 & 0.06 \\
\hline dual & -0.049 & -0.78 & 0.44 \\
\hline yr88 & -0.838 & -6.71 & 0.00 \\
\hline yr89 & -0.721 & -6.14 & 0.00 \\
\hline fslh & 0.018 & 0.27 & 0.79 \\
\hline In (Listp-Salep) & 4.454 & 9.56 & 0.00 \\
\hline lntass & 0.656 & 7.21 & 0.00 \\
\hline
\end{tabular}

This table reports regression coefficients for the DOM hedonic model. The dependent variable is the log of days on market. The independent variables are: dual (a dual variable indicating the presence of dual agency), dummy variables for year of sale and for fee-simple contracts $(f s l h)$, the log of the difference between list and sales price, and the log of the total assessed value of the residence (Intass). Heteroscedasticity is corrected using a biweighting algorithm. This table presents the estimation in preand post-legislation period for observations below the median sales price in each period and the data for observations above the median price 
Table 4 Seemingly unrelated regression model: (a) sales price and (b) days on market

\begin{tabular}{|c|c|c|c|}
\hline & Coefficient & $t$-stat & $P$-value \\
\hline \multicolumn{4}{|c|}{$\begin{array}{l}\text { 1977-1980; Equation (a): Dependent variable } \ln (S A L E P) \\
R^{2}=0.8762\end{array}$} \\
\hline Intercept & 0.758 & 15.17 & 0.00 \\
\hline dual & -0.031 & -2.49 & 0.05 \\
\hline $\mathrm{yr} 78$ & 0.204 & 14.14 & 0.00 \\
\hline $\mathrm{yr} 79$ & 0.431 & 31.85 & 0.00 \\
\hline fslh & 0.129 & 18.85 & 0.00 \\
\hline lntass & 0.930 & 96.83 & 0.00 \\
\hline \multicolumn{4}{|c|}{$\begin{array}{l}1977-1980 ; \text { Equation (b): Dependent variable: } \ln (D O M) \\
R^{2}=0.0522\end{array}$} \\
\hline Intercept & 1.343 & 4.57 & 0.00 \\
\hline dual & -0.092 & -2.41 & 0.02 \\
\hline $\mathrm{yr} 78$ & 0.540 & 6.39 & 0.00 \\
\hline $\mathrm{yr} 79$ & 0.508 & 6.39 & 0.00 \\
\hline fslh & 0.103 & 2.56 & 0.01 \\
\hline ln (Listp-Salep) & 3.437 & 10.50 & 0.00 \\
\hline lntass & 0.401 & 7.06 & 0.00 \\
\hline \multicolumn{4}{|c|}{ 1987-1989; Equation (a): Dependent variable $\ln (S A L E P)$} \\
\hline \multicolumn{4}{|c|}{$R^{2}=0.8666$} \\
\hline Intercept & 0.966 & 23.47 & 0.00 \\
\hline dual & -0.017 & -1.54 & 0.15 \\
\hline $\mathrm{yr} 88$ & -0.485 & -31.39 & 0.00 \\
\hline yr89 & -0.314 & -21.47 & 0.00 \\
\hline fslh & 0.138 & 19.33 & 0.00 \\
\hline lntass & 0.958 & 93.87 & 0.00 \\
\hline \multicolumn{4}{|c|}{$\begin{array}{l}1987-1989 \text {; Equation (b): Dependent variable: } \ln (D O M) \\
R^{2}=0.596\end{array}$} \\
\hline \multicolumn{4}{|c|}{$R^{2}=0.0596$} \\
\hline Intercept & 1.437 & 6.17 & 0.00 \\
\hline dual & -0.093 & -2.44 & 0.02 \\
\hline yr88 & -0.699 & -8.06 & 0.00 \\
\hline yr89 & -0.689 & -8.34 & 0.00 \\
\hline fslh & 0.127 & 3.19 & 0.00 \\
\hline In (Listp-Salep) & 3.318 & 10.15 & 0.00 \\
\hline lntass & 0.510 & 8.76 & 0.00 \\
\hline
\end{tabular}

This table reports coefficients from a seemingly unrelated regression model for equation (a): the log of sales price (SALEP) and equation (b): the log of days on market (DOM). The independent variables in equation (a) are: dual (a dual variable indicating the presence of dual agency); dummy variables for years; fslh (a dummy variable for fee-simple contracts); the log of the total assessed value of the residence (Intass). Equation (b) uses DUAL; dummy variables for years; FSLH; the log of the difference between listing and sales price; lntass. This table presents the estimation results for the pre- and post-legislation periods, respectively

\section{Seemingly Unrelated Regression Model}

There is an important interaction between the chosen listing price and a transaction's days on market; clearly a listing that is high relative to its comparables would be expected to experience a longer time to sale. ${ }^{20}$ Table 4 summarizes the results of our final test of the impact of the legislation and of dual agency. It presents the estimation of a seemingly unrelated regression (SUR) model with equations for the log of sales price (equation a) and the log of days on market (equation b). ${ }^{21}$ The two equations

\footnotetext{
${ }^{20}$ See Anglin et al. (2003) for an analysis of this tradeoff.

${ }^{21}$ Knight (2002) analyzes the causes and effects of changes in listing prices.
} 
essentially mimic the independent estimation done in Tables 2 and 3, but here the SUR model accounts for the presence of correlated errors in the simultaneous estimation.

Table 4 presents the estimation in the 1977-1980 period. The results are broadly consistent with the earlier estimations. In the sales price equation, the dual coefficient is negative and significant (although with a smaller magnitude than observed in Table 2); in the days on market equation, the dual variable is again negative and significant. After the legislation, Table 4 confirms the earlier estimation results. The impact of dual agency on the sales price is insignificant while it significantly reduced the days on market. Thus, we have presented significant evidence that, prior to the legislation, transactions involving a dual agency relationship lead to a lower sales price and a shorter time on market. This is consistent with the notion that buyers gained and sellers lost (since the relatively shorter time to sale has much less economic impact than the significantly lower sale price). However, in a climate of disclosed dual agency, its impact on sales price seems to have been greatly reduced, while the days on market impact is retained.

\section{Conclusions}

It is reasonable to expect that dual agency gives the dual agents more information about their clients' reservation prices. The agents could then potentially exploit this information by matching the buyer and seller at a sale price different from that achieved without dual agency. Our empirical work analyzes the 1987 Hawaii legislation that mandated full disclosure of dual agency relationships. The assumption being the disclosure of a dual agency relationship would mitigate the power of the agents to influence buyer's and seller's negotiation strategies. To estimate the economic impact of disclosed and undisclosed dual agency, we estimate hedonic models for the log of sale price and the log of days on market before and after the legislation. Our results suggest that agents did react to the legislation. The frequency of dual agency declined in the post-legislation period (from 44 to $29 \%$ of all listings). Our empirical analysis suggests that dual agency significantly reduced the sales price, but that the influence was much smaller after the legislation. The estimated coefficients suggest that the reduction in sales price due to dual agency was approximately $8.0 \%$ pre-legislation and $1.4 \%$ post-legislation. This estimation is robust to partitioning the sample by transaction size. In addition, dual agency significantly decreased the time on market by approximately $8.5 \%$ pre-legislation and $8.1 \%$ post-legislation, although the influence was only present for lower priced residences. These results are confirmed using a seemingly unrelated regression model. 
We view this empirical analysis as a contribution to the extant research demonstrating the economic importance of agency relationships. Viewed in its most negative light, our data are consistent with the hypothesis that, prior to the regulation, the presence of a dual agency arrangement could have lead to agents reducing their effort levels by matching buyer and seller at a lower selling price and in a shorter timeframe than otherwise. After the legislation the impact of dual agency is significant only in the reduction in time to sale. Thus proponents of the legislation can interpret our analysis as consistent with the notion that the legislation was warranted and had its desired effect.

\section{References}

Anglin, P. (1997). The contribution of buyer brokerage. Journal of Housing Economics, 6, 277-292.

Anglin, P., Rutherford, R., \& Springer, T. (2003). The tradeoff between the selling price of residential properties and time-on-the-market: The impact of price setting. Journal of Real Estate Finance and Economics, 26, 95-111.

Bajtelsmit, V. L., \& Worzala, E. (1997). Adversarial brokerage in residential real estate transactions: The impact of separate buyer representation. Journal of Real Estate Research, 14, 65-75.

Black, R., \& Nourse, H. (1995). The effect of different brokerage modes on closing costs and house prices. Journal of Real Estate Research, 10, 87-98.

Blumenthal, K. (1995). Could your broker be a double agent? Wall Street Journal, Sept. 8.

Brown, R. B., Grohman, J., \& Valcarel, M. (1995). Real estate brokerage: Recent changes in relationships and a proposed cure. Creighton Law Review, 29, 29-97.

Bryan, T. B., \& Colwell, P. (1982). Housing price indices. Research in Real Estate, 2, 57-84.

Bryant, J. A., \& Epley, D. R. (1992). The conditions and perils of agency, dual agency and undisclosed agency. Real Estate Law Journal, 117.

Case, K., \& Shiller, R. (1989). The efficiency of the market for single-family homes. American Economic Review, 79(1), 125-137.

Clapp, J., \& Giaccotto, C. (1992). Estimating price indices for residential property: A comparison of repeat sales and assessed value methods. Journal of the American Statistical Association, 87(418), 300-306.

Curran, C., \& Schrag, J. (2000). Does it matter whom an agent serves? Evidence from recent changes in real estate agency law. Journal of Law and Economics, XLIII, 265-284.

Diamond, D. W. (1989). Reputation acquisition in debt markets. Journal of Political Economy, 97(4), 828862. 
Elder, H., Zumpano, L., \& Baryla, E. (2000). Buyer brokers: Do they make a difference? Their influence on sale price and search duration. Real Estate Economics, 28, 337-362.

Federal Trade Commission (1983). The residential real estate brokerage industry. December, Staff Reports.

Frew, J. (1987). Multiple listing: Participation in the real estate brokerage industry. Journal of Urban Economics, 21, 272-286.

Genesove, D., \& Mayer, C. (1997). Equity and time to sale in the real estate market. American Economic Review, 87, 255-269.

Hawaii Real Estate Commission (1987). Understanding agency disclosure.

Holmström, B. (1979). Moral hazard and observability. Bell Journal of Economics, 13, 924-940.

Knight, J. (2002). Listing price, time on market, and ultimate selling prices: Causes and effects of listing price changes. Real Estate Economics, 30, 213-237.

Mayer, C. (1995). A model of negotiated sales applied to real estate auctions. Journal of Urban Economics, 38, 1-22.

Rutherford, R. C., Springer, T. M., \& Yavas, A. (2005). Conflicts between principals and agents: Evidence from residential brokerage. Journal of Financial Economics, 76, 627-665.

Salant, S. W. (1991). For sale by owner: When to use a broker and how to price the house. Journal of Real Estate Finance and Economics, 4, 157-173.

Sappington, D. (1991). Incentives in principal-agent relationships. Journal of Economic Perspectives, 5, 45-66.

Shapiro, C. (1982). Consumer information, product quality, and seller reputation. Bell Journal of Economics, 13, 20-35.

Shapiro, C. (1983). Premiums for high quality products as returns to reputations. Quarterly Journal of Economics, 98, 659-679.

Springer, T. M. (1996). Single-family housing transactions: Seller motivations, price, and marketing time. Journal of Real Estate Finance and Economics, 13(2), 237-254.

Wheaton, W. (1990). Vacancy, search, and prices in a housing market matching model. Journal of Political Economy, 98(6), 1270-1291.

Williams, J. T. (1995). Pricing real assets with costly search. Review of Financial Studies, 8, 55-90.

Yavas, A. (1992). A simple search and bargaining model for real estate markets. AREUEA Journal, 20(4), 533-548. 
Yavas, A. (1995). Can brokerage have an equilibrium selection role? Journal of Urban Economics, 37, 1737.

Yavas, A., Miceli, T., \& Sirmans, C. F. (2001). An experimental analysis of the impact of intermediaries on the outcome of bargaining games. Real Estate Economics, 29, 251-276.

Yinger, J. (1981). A search model of real estate broker behavior. American Economic Review, 71(4), 591604. 